\title{
Design of experimental bench based on motion controller
}

\author{
Hong-Yan $\mathrm{SHI}^{1, \mathrm{a}}$, \\ ${ }^{1}$ Inner Mongolia University for the Nationalities, College of Mechanical Engineering, Tong Liao, \\ 028000, China. \\ ajdxashy@126.com
}

Keywords: Experimental bench, Motion controller, Control system.

\begin{abstract}
The numerical control technology is an important indicator to measure a country's comprehensive national strength and national defense strength, with the continuous development of China's science and technology, NC technology has been greatly improved, at the same time, NC personnel is also required correspondingly. But the problems of poor experimental conditions in the process of personnel training is exist, it cannot do very well in practical teaching, a kind of experimental bench is designed based on the motion controller in this paper, the bench has the advantages of simple structure, it is economical and practical, which provides a new way for the teaching of numerical control technology.
\end{abstract}

\section{Introduction}

After years of development, $\mathrm{CNC}$ technology has become the core of modern manufacturing technology [1]. The level of CNC equipment, CNC technology ownership and manufacturing capabilities of CNC equipment have become an important symbol to measure a country's level of industrial modernization. The development of numerical control technology is the foundation of national defense construction and the guarantee of national economic development [2]. With the development of China's economy and the progress of science and technology, the manufacturing industry has put forward higher requirements for equipment, numerical control equipment has become the inevitable trend of the development of CNC technology, integrated personnel is urgently needed, and it puts forward higher requirements on the CNC talents cultivation [3]. But the training of $\mathrm{NC}$ personnel in our country has certain problems, the main reason are, the curriculum and teaching content is not reasonable, equipment is backward [4]. But the numerical control technology and electromechanical integration technology are practical technology, it must carry on the practice experience, the experimental conditions are insufficient to meet the demand of the teaching [5]. In this paper, kind of experimental bench is designed based on the motion controller, the bench has the advantages of simple structure, it is economical and practical, it can effectively solve the problem of insufficient experimental conditions. It has a certain practical significance.

\section{Overall design of the bench}

The mechanical structure design of the bench. The bench has two degrees of freedom, respectively they are $\mathrm{X}$ and $\mathrm{Y}$ directions. It is shown in Figure 1, the bench is driven by two motors, servo motor is connected with the ball screw through the gear mechanism, the ball screw is connected with the bench, the servo motor rotates to drive the bench. A photoelectric switch is put on the bench, which is used to control the bench to find zero, it provided with a limit switch at the end of the bench, so as to prevent the overrun movement of the bench, it is used to ensure the work station safety. 


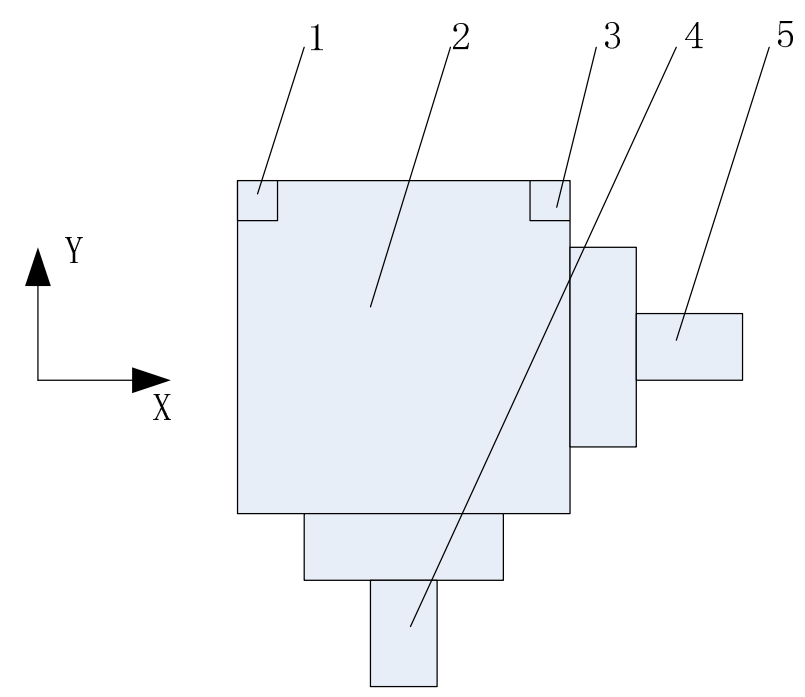

1. Limit switch 2.Bench 3.Zero returning switch 4.Y axis motor 5.X axis motor

Figure 1.The mechanical structure design

The control system design of the bench. The control system of the bench is shown in Figure 2, the control system consists of PC machine, motion controller, servo driver and servo motor. The core of the control system is the motion controller, motion controller receives the signal from the PC machine, and controls the bench, the bench makes the corresponding movement. The PC and motion controller is connected by Ethernet, they can communicate directly. Zero returning switch and limit switch are directly connected with the motion controller, in the motion of the bench, if the zero returning switch or the limit switch is triggered, the system automatically receives the feedback signal, and makes the corresponding action according to program to control the bench.

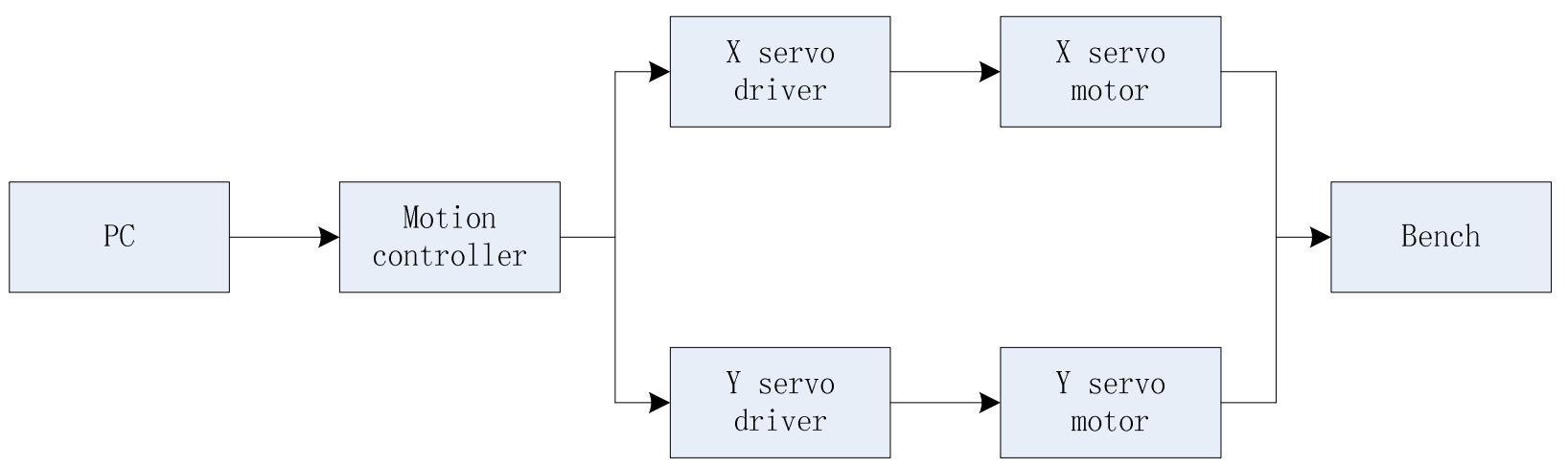

Figure 2.The hardware integration

\section{Software design}

Software structure design. The motion controller is the core of the control system of the bench. As shown in Figure 3, the control system uses the form of upper and lower computer. The motion controller is operated based on PC, it only has the operation environment, there is no development environment, so it is necessary to use $\mathrm{PC}$ as the host machine, motion controller as slave machine. As shown in Figure 4, the software design adopts modularization, hierarchical way, they are divided into management module, parameter module, motion control module according to the different levels. The management module and the module parameters are completed by PC, including the preparation and management, program settings and display; the motion control module is completed by the motion controller, including motion control and logic control. 


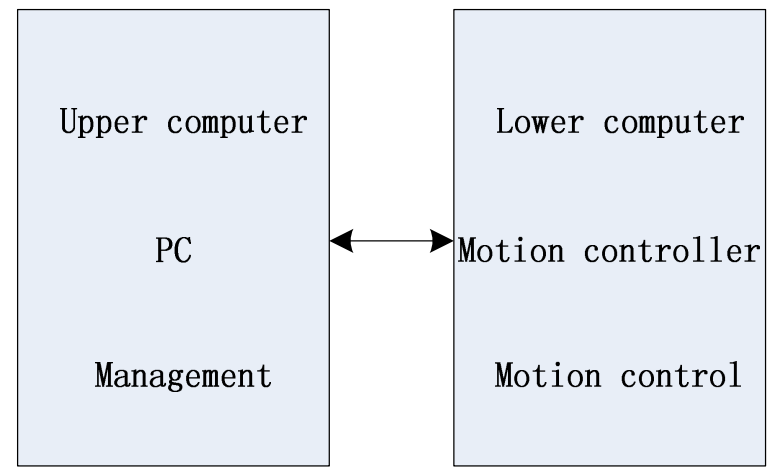

Figure3. The mode of control system

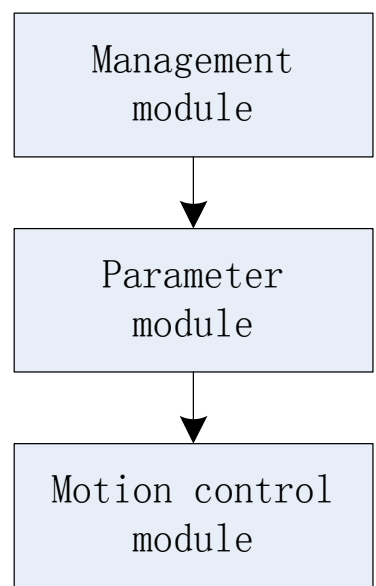

Figure4. The modular design of software

I/O design. The sending and receiving signal is of system through the I/O interface of controller, including the zero returning signals, limit signals, indication signal, etc. The design of $\mathrm{I} / \mathrm{O}$ system is shown in table 1 .

Table1. System I/O design

\begin{tabular}{cccc}
\hline & Input & & Output \\
\hline IN0 & $\begin{array}{c}\text { Zero returning } \\
\text { signal 1 } \\
\text { Zero returning } \\
\text { IN1 }\end{array}$ & OUT0 & Indication signal 1 \\
Limit signal 1 & OUT1 & Indication signal 2 \\
IN2 & Limit signal 2 & OUT3 & Indication signal 3 \\
IN3 & & OUT4 & Indication signal 4 \\
& & OUT5 & Indication signal 5 \\
& & & \\
\hline
\end{tabular}

Program flow design. Program flow design is shown in figure 5. First of all, the system does initialization, inspecting operation state of system, if there is an error, the system will be given instructions, if there is no error, after the initialization, $\mathrm{X}$ axis and $\mathrm{Y}$ axis respectively comes back to the origin, then set parameter programming. It can be programmed only after determining the bench reference point, otherwise there is no programming reference, it may cause the bench cross-border operation. After programming the bench will move correspondingly, if the bench is beyond the limit switch position, the system will automatically stop running and alarm. The operating status can be observed in the process of movement, including the $\mathrm{X}$ and $\mathrm{Y}$ axis velocity and displacement etc. 


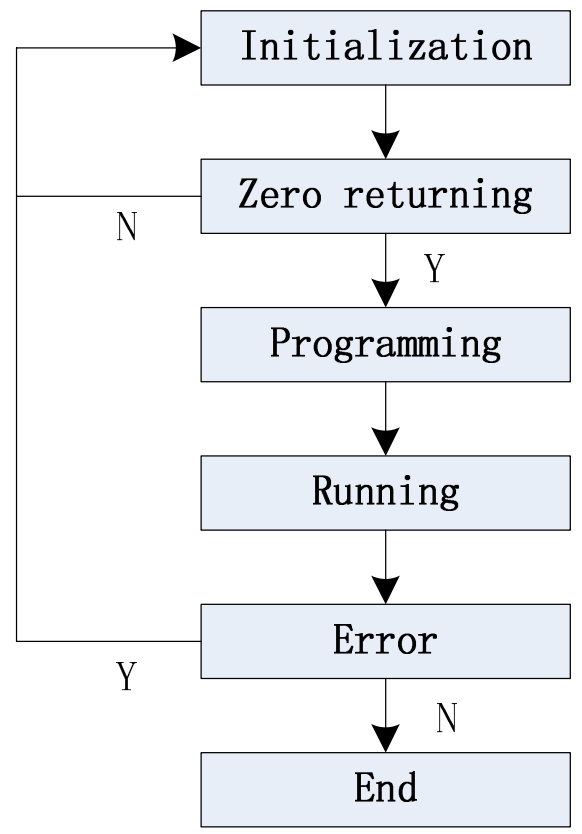

Figure5. Work flow

\section{Summary}

According to the problem of insufficient experimental conditions in the course of CNC technology and electromechanical integration of, a kind of experimental bench is designed based on the motion controller in this paper, the bench can be used for CNC technology or mechatronics course, although this system cannot achieve the high-end CNC system, but this system is economical and practical, it is specifically for teaching the development, operation and maintenance costs are not high, it effectively solves the difficult problem of the students. A new method is proposed for the training of NC technology and mechatronics talents.

\section{References}

[1] Wen Guang, Ma Hongwei. Current situation and development trend of CNC technology [J]. Mechanical Engineer, 2003, (1): 9-12.

[2] Zhang Fuyuan, Fang Jianglong. On the development of CNC technology in China [J]. Chinese mechanical engineering, 1999, 10 (10): 1100-1103.

[3] Lu Qijian, Liu Mingdeng. Advances in numerical control technology [J]. Manufacturing technology and machine tool, 2002, (5): 5-7.

[4] Ji Hua Tian. Demand analysis of NC technical personnel [J]. Liaoning Journal of higher vocational education, 2008, 10 (7): 27-28.

[5] Wang Haigen, Cheng Guobiao, Fang Zhufang. Exploring the NC technology practice teaching [J]. Experimental technology and management,2008, 25 (2): 92-94. 